\title{
Developing the APS-SE: Translation and Cultural Adaptation of the Abbey Pain Scale (APS) to A Swedish Care Context.
}

\author{
Per Fransson \\ Umeå University: Department of Nursing \\ Lisa Martinsson \\ Umeå Universityu
}

Sussi Tegenborg ( $\sim$ sussi.tegenborg@onkologi.umu.se )

Umeå University https://orcid.org/0000-0002-0125-629X

Research article

Keywords: pain assessment, dementia, palliative care, end-of-life care, Abbey Pain Scale, communicative dysfunction

Posted Date: November 5th, 2020

DOI: https://doi.org/10.21203/rs.3.rs-100676/v1

License: (c) (i) This work is licensed under a Creative Commons Attribution 4.0 International License. Read Full License 


\section{Abstract}

Background. The Abbey Pain Scale (APS) is an Australian observational scale for assessing pain in nursing home residents with end-stage dementia. The APS is widely used both in nursing homes and by other caregivers in Sweden for people with various diseases. No validated peer-reviewed translation to Swedish is available. The aim of this study was to translate and culturally adapt the APS for persons with end-stage dementia in Sweden.

Methods. After an initial discussion of concepts, the APS was translated into Swedish and back into English to check for accuracy. The resulting Swedish version was then revised and culturally adapted through a series of interviews with nursing assistants, nurses, and physicians $(n=11)$ to develop the final Swedish version - the APS-SE.

Results. The interviews emphasized the need to adapt the scale not only to the Swedish culture, but also to the educational and linguistic differences among the various staff members using it in different care contexts.

Conclusion: This study highlights the importance of introducing new staff members carefully to the instrument, the APS-SE, to ensure understanding of all words and items.

\section{Key Message}

A Swedish version of the Abbey Pain Scale (APS), an observational pain assessment tool for people with end-stage dementia, has been developed for use in Sweden: the APS-SE.

\section{Background}

The most commonly used scales of self-reported pain are the visual analogue scale (VAS), the numeric rating scale (NRS), and the verbal rating descriptor scale (VRS/VDS). In general, NRS is preferred by the cognitively intact, while VRS/VDS is favoured by the elderly and those with mild to moderate cognitive impairment $(1,2)$.

When a patient can no longer communicate verbally, as with people with late-stage dementia, the focus shifts from self-reporting to observation for expressions of pain. The need for sufficient observational scales is evident, since dementia is the fifth most common cause of death worldwide (3), and the prevalence of reported pain among people with dementia or cognitive impairment in age care facilities ranges from $15-43 \%(4)$.

Several observational scales for patients with dementia or cognitive impairment are available in English (5). The White Paper on Dementia from European Association for Palliative Care, EAPC, does not specify which of these observational scales should be used (6). In Sweden three different pain assessment tools 
are recommended by the Swedish National Guideline for Palliative Care in end-of-life care - one of these observational tools is the Abbey Pain Scale, APS (7).

The APS was created by Abbey, Piller, De Bellis, et al in Australia 2004 to assess pain in people with lateor end-stage dementia in residential aged care homes (8). The scale consists of six indicators:

vocalisation, facial expression, change in body language, behavioural change, physiological change, and physical change. Each indicator was provided with different examples such as 'vocalisation, e.g., whimpering, groaning, crying'. The person's total pain is assessed by adding up the indicator scores and ranges from $0-2$ (no pain) to $14+$ (severe pain). The rating is finished by classifying the pain as chronic, acute, or acute on chronic (8).

The APS was specifically created to assess pain in people with dementia in residential aged care homes (8). It is estimated that between $40 \%$ to $75 \%$ of all patients in nursing homes in Sweden live with dementia (9). The proportion of people who die from a dementia-related cause in hospitals differs between countries (10). In Sweden, a rough approximation is that $5 \%$ of all who die from dementia die in acute hospital wards (11).

Furthermore, in Sweden the APS is not only used to assess pain on people with dementia, but also applied on people in need of palliative care in general. Today the APS is widely deployed in a variety of different care settings. e.g. in different departments in hospitals, in home care units and in hospices according to Maria Andersson, register manager of the Swedish Register of Palliative Care, the SRPC [personal communication]. The SRPC is a quality register whose purpose is to improve quality of end-oflife care regardless of care setting (12). It is also the main distributor of the most universially used version of the APS in Sweden (13).

The APS has previously been translated and tested in Japan (14), Denmark (15), and Italy (16). To the best of our knowledge, no peer-reviewed culturally adapted translation to Swedish is available.

\section{Aim}

The aim of this study was to translate and culturally adapt the APS for persons with end-stage dementia in Sweden.

\section{Methods}

Based on guidelines for translation and cross-cultural adaptation $(17,18)$ the Swedish version of APS, the APS-SE, was generated as follows in Table 1.

After meeting with the expert group, two items ('skin tears' and 'fidgeting') remained unresolved and underwent conceptual phase 2 . We again searched the literature and consulted colleagues and experts for conceptualisation of these terms. The alterations of those remaining items were then proposed to the expert group and accepted, resulting in the initial Swedish version of the APS, the APS-SE. 
Interviews with physicians, nurses, and nursing assistants were conducted to expose any comprehension problems with the APS-SE. Purposeful sampling was used to achieve a variation in gender, age, occupation (nurse, nursing assistant, or physician), workplace, experience in using the APS, and Swedish versus other native language.

To be included, interviewees had to be adult health care staff working in a geriatric department, nursing home, palliative care, or an emergency department and to provide oral and written consent.

With the new translation at hand, each interviewee was instructed to visualise a specific person while completing the APS-SE. A semi-structured interview guide developed by the authors was used during the interviews, with example item such as 'Describe your thought process when you fill in question 1'. A pilot interview was conducted to test the interview guide. All the interviews were audio recorded and transcribed.

After listening to each interview and reading the transcript, two authors (ST and LM) individually identified ambiguous items. Those items were then, if needed, altered through consensus by ST and LM and the revised version of the APS-SE were used for the next interview. This process was repeated until nothing essentially new was uncovered during the interviews. A total of 11 interviews were conducted until the fifth and final version of the APS-SE was established.

\section{Results}

After the pilot interview, no alterations of the interview guide were found to be necessary. For interviewee demographics, see Table 2. 
Table 1

Translation and cultural adaptation of the Swedish version of APS, the APS-SE.

\section{Planning and conceptual phase}

\section{Literature review of guidelines on translation, pain assessment tools, and palliative care in Sweden (ST, PF, LM)}

\section{Informal group discussion on concepts of the APS items with health care staff: ST, LM, a senior lecturer in nursing, three nurses in palliative care, and a manager of a palliative care unit}

\section{Forward translation}

Forward translation separately by two native Swedish speakers:

a professional translator without prior medical knowledge and a specialist in palliative medicine Consensus of the versions mediated by the second author (PF)

\section{Backward translation}

Blinded ${ }^{a}$ backward translation separately by two native English speakers: a professional translator without prior medical knowledge and a nurse working in a palliative care setting

Consensus on the versions mediated by the second author (PF)

\section{Expert review}

Expert group discussion (ST, PF, LM, and all translators) on the translations of items

Consensus on all items except two

\section{Conceptual phase 2}

Literature review, consultation with colleagues and experts on the two remaining items (ST, LM)

Proposing new alternatives and getting consensus for the two remaining items from the expert group (ST, PF, LM, and all translators)

Agreement on the initial Swedish APS version for testing

\section{Interviews, analysis, and adjustments}

Pilot interview to test the semi-structured interview guide

Interviews of staff working with people with dementia

Alterations of the Swedish version of APS if needed according to the interviews

Repeated interviews and alterations until no new essential information was revealed in the interviews

Final version of the Swedish AP: the APS-SE

${ }^{a}$ Blinded translation: to minimise any bias, translators had no previous knowledge of the original APS. 
Table 2

Interviewee demographic, $\mathrm{n}=11$

\begin{tabular}{|c|c|c|}
\hline \multirow[t]{3}{*}{ Occupation, n (\%) } & Nursing assistant & $2(18 \%)$ \\
\hline & Nurse & $3(27 \%)$ \\
\hline & Physician & $6(55 \%)$ \\
\hline \multirow[t]{2}{*}{ Age, range (years) } & Female & $20-33$ \\
\hline & Male & $33-58$ \\
\hline \multirow[t]{2}{*}{ Gender, n (\%) } & Female & $6(55 \%)$ \\
\hline & Male & $5(45 \%)$ \\
\hline \multirow{3}{*}{$\begin{array}{l}\text { Working with people with dementia, } \\
\text { range (years) }\end{array}$} & Nursing assistant & $1-8$ \\
\hline & Nurse & $2-19$ \\
\hline & Physician & $5-29$ \\
\hline \multirow[t]{5}{*}{ Workplace, n (\%) } & Residential care unit & $4(36 \%)$ \\
\hline & $\begin{array}{l}\text { Specialised palliative home care unit } \\
\text { (University Hospital) }\end{array}$ & $1(9 \%)$ \\
\hline & Geriatric department (University Hospital) & $2(18 \%)$ \\
\hline & Emergency department & $4(36 \%)$ \\
\hline & (University Hospital) & \\
\hline \multirow[t]{2}{*}{ Native Swedish speaker, n (\%) } & Yes & $7(64 \%)$ \\
\hline & No & $4(36 \%)$ \\
\hline \multirow[t]{2}{*}{ Previous experience with APS, n (\%) } & Yes & $6(55 \%)$ \\
\hline & No & $5(45 \%)$ \\
\hline
\end{tabular}

Conceptualisation phase

Most key concepts in the APS were found easily understandable in relation to healthcare in Sweden. The term 'resident' was used in the original version of the APS. In Sweden, several different institutions care for people with dementia: hospitals, nursing homes, in-home care, and hospices. Since all these institutions use different terms (e.g., 'patient', 'resident'. or 'guest') we settled on the neutral designator 'person' in the APS-SE.

The concept 'acute on chronic pain' was not fully understood and lacked a definition by the developers (8). 'Acute on chronic pain' does not exist as a diagnosis in the International Classification of Diseases-11 (ICD-11) (19), a classification system developed by World Health Organization (WHO) for clinical and 
research purposes (20). After consulting with several colleagues, the authors finally decided on 'kronisk och akut' (chronic and acute) pain.

Translation process

The following issues were identified:

\section{Q1}

The word 'whimpering' needed dual Swedish translations to be well recognised by the non-native Swedish-speaking interviewees.

Q2

This question and translation was well understood; no alterations were needed.

Q3: The translation of 'fidgeting' required several alterations. Some synonyms were well understood by native Swedish speaking interviewees, but not as well comprehended by non-native Swedish speakers. The authors finally agreed on: 'move restlessly (e.g., to fiddle or shake one's leg)'.

'Withdrawn' was interpreted both physically and mentally. As in English, the word has a dual meaning in Swedish. Both interpretations were found acceptable, since both types of change had been registered by the interviewees. This was also confirmed in discussions with experienced specialists in geriatrics.

\section{Q4}

In the first version of the Swedish APS, 'refusal to eat' was translated to matvägran, which was perceived to have a negative connotation in Swedish. It suggested the behaviour of children rather than adults. The new translation vill inte äta ('does not want to eat') was received as neutral.

\section{Q5}

The translations of 'flushing' and 'pallor' to rodnad and blekhet were accepted, as these terms are commonly used in medical records according to the emergency medicine specialists we interviewed. However, the items were not always applicable, especially if the person had a darker skin tone. Prior knowledge of the patient by the physician, accompanying staff, or relatives was considered important for assessing the items accurately.

\section{Q6}

Hudfliksskada is a validated Swedish translation of the term 'skin tears' (21). The interviewees were divided, however; not everyone grasped the translation, and some needed additional explanation. Since hudfliksskada was validated as recently as 2018 , the term will probably be more commonly recognised in time. 
The word 'contractures' has a Swedish medical equivalence in kontraktur. Because this word was not understood by the nursing assistants, an additional explanation was added: kan inte böja eller sträcka ut en led (kontraktur), i.e., 'cannot bend or straighten a joint (contratures)'.

The translation for the scale 'no, mild, moderate, or severe' pain was considered easy to understand.

After these changes, none of the items were considered inappropriate.

\section{Discussion}

In this study we describe the process of developing a Swedish version of the APS, APS-SE, for use in Sweden on people with end-stage dementia. While developing the APS-SE it became evident that focusing on the semantics of each individual word, by using the forward and backward technique, was not enough. It was equally important to test the translation by interviewing the targeted staff.

In Sweden the APS is used by nursing assistants, nurses, and physicians with various cultural, ethnic, and linguistic backgrounds. The medical education among nursing assistants varies, leading the Swedish National Board of Health and Welfare to invest roughly 85 million euros from 2011 to 2014 to enhance education among nursing assistants (22). Today about $20 \%$ of nursing assistants in nursing homes still do not fulfil an acceptable standard of education according to the Swedish National Board of Health and Welfare (23).

The first versions of the translation revealed problems due to differences in education and/or linguistic background among the interviewees. Several of the interviewed nurses also noted that when introducing the APS to a new staff member, it was important to provide a thorough explanation of the assessment scale itself and to ensure that the staff understood all the words included. This was again especially crucial if the staff was a nursing assistant and/or had a non-Swedish first language. To facilitate understanding for all staff members, we needed to add some explanatory words to certain terms.

Throughout the interviews, physicians, nurses, and nursing assistants expressed the importance of having prior knowledge of the patients when assessing the different items. This dilemma has been addressed in previous studies with nurses working in the emergency department, who valued help from relatives and carers in assessing the pain of people with cognitive impairment $(24,25)$. The need for familiarity with the person also made the nurses consider the APS more suitable in care homes, in-home care, or palliative care than in the emergency department (25).

Some of the items, such as pallor or flush in people with darker skin tone, were especially difficult to judge without any prior familiarity with the person. Only the physician trained in Africa, with experience judging 'normal' skin tones in different African countries, had less difficulty than others in distinguishing pallor in people with darker skin tones. Many skin-care guidelines apply mainly to people with fair skin. Natural or halogen lighting is recommended when assessing people with darker skin, since other lighting can give them a misleading bluish tint (26). 
Today the APS is already used in Sweden in a multitude of different palliative settings, regardless of whether all the items in the APS are applicable on people receiving palliative care or not. The need to assess pain in people receiving palliative care makes further research and validation of the APS for such people necessary and recommended.

Strengths and limitations

A strength with this study is the repeated interviews to test comprehension of the newly translated APSSE in various care settings, not just in nursing homes. Identifying early in the interviews the significance of education and the interviewee's native tongue, we also actively recruited interviewees to obtain diversity in both educational and linguistic background.

Since nothing essentially new arose during the last three interviews, we decided to settle after interview number 11. This is consistent with a study from 2006 that showed that saturation occurred within the first 12 interviews (27).

\section{Conclusion}

The completed translation and cultural adaptation of the original Australian APS has generated a Swedish version, the APS-SE, for use in Sweden on patients with end-stage dementia. This study highlights the importance of introducing new staff members carefully to the instrument to ensure understanding of all words and items. The APS and APS-SE may be less applicable for assessing darker skin tones compared to lighter, which is a limitation of the instrument.

\section{Abbreviations}

APS: Abbey Pain Scale, APS-SE: the Swedish version of APS, EAPC: European Association for Palliative Care, SRPC: the Swedish Register of Palliative Care, WHO: World Health Organization.

\section{Declarations}

\section{Ethics and consent to participate}

This study was approved by the Regional Ethical Review Board in Umeå, Sweden, (registration number 2017/504-31).

\section{Consent for publication}

Each interviewee gave oral and written consent to participate and publish the data.

The developer of the APS, Dr Jennifer Abbey, was contacted and provided her permission for us to translate and culturally adapt the APS to Swedish. 
Availability of data and materials

National legislation and ethics boards in Sweden do not permit the authors to share raw data.

\section{Competing interest}

The authors declare that they have no competing interests.

\section{Funding}

This work was supported by the Department of Oncology, Norrlands University Hospital, Umeå, Sweden under [grant number 52903/7002228]; Cancerforskningsfonden i Norrland, Umeå, Sweden under [grant number AMP 18-922]; and Västerbottens läns landstings ettåriga forskningsanslag, Umeå, Sweden [grant number 7003533]. The funding sources were not involved in the study.

\section{Authors' contributions}

ST, PF and LM planned the study. PF participated as a mediator during the forward and backward translation. ST and LM interviewed the first 5 interviewees together and ST the last 6 . ST and LM read each transcript and in consensus revised each version of the APS-SE. ST wrote the first manuscript draft and LM and PF made critical revisions. All authors approved the final version.

\section{Acknowledgements}

We thank the interviewees and all our colleagues in Palliative Medicine at Norrlands University Hospital for all their contributions and support.

\section{References}

1. Karcioglu O, Topacoglu H, Dikme O, Dikme O. A systematic review of the pain scales in adults: Which to use? The American journal of emergency medicine. 2018;36(4):707-14.

2. Hjermstad MJ, Fayers PM, Haugen DF, Caraceni A, Hanks GW, Loge JH, et al. Studies comparing Numerical Rating Scales, Verbal Rating Scales, and Visual Analogue Scales for assessment of pain intensity in adults: a systematic literature review. Journal of pain and symptom management. 2011;41(6):1073-93.

3. World Health Organization. The top 10 causes of death. https://www.who.int/news-room/factsheets/detail/the-top-10-causes-of-death. Accessed 8 May 2019.

4. Tan EC, Jokanovic N, Koponen MP, Thomas D, Hilmer SN, Bell JS. Prevalence of Analgesic Use and Pain in People with and without Dementia or Cognitive Impairment in Aged Care Facilities: A Systematic Review and Meta-Analysis. Current clinical pharmacology. 2015;10(3):194-203.

5. Lichtner V, Dowding D, Esterhuizen P, Closs SJ, Long AF, Corbett A, et al. Pain assessment for people with dementia: a systematic review of systematic reviews of pain assessment tools. BMC geriatrics. 
$2014 ; 14: 138$.

6. van der Steen JT, Radbruch L, Hertogh CM, de Boer ME, Hughes JC, Larkin P, et al. White paper defining optimal palliative care in older people with dementia: a Delphi study and recommendations from the European Association for Palliative Care. Palliat Med. 2014;28(3):197-209.

7. Regionala cancercentrum i samverkan. Nationellt vårdprogram för palliativ vård i livets slutskede. https://www.cancercentrum.se/globalassets/vara-uppdrag/rehabilitering-palliativvard/vardprogram/natvp_palliativvard_vers.2.1_dec2016.pdf. Accessed 8 May 2019.

8. Abbey J, Piller N, De Bellis A, Esterman A, Parker D, Giles L, et al. The Abbey pain scale: a 1-minute numerical indicator for people with end-stage dementia. Int J Palliat Nurs. 2004;10(1):6-13.

9. Socialstyrelsen. Demenssjukdomarnas samhällskostnader i Sverige 2012. https://www.socialstyrelsen.se/globalassets/sharepoint-dokument/artikelkatalog/statistik/2014-63.pdf. Accessed 8 May 2020.

10. Reyniers T, Deliens L, Pasman HR, Morin L, Addington-Hall J, Frova L, et al. International variation in place of death of older people who died from dementia in 14 European and non-European countries. Journal of the American Medical Directors Association. 2015;16(2):165-71.

11. Martinsson L, Lundström S, Sundelöf J. Better quality of end-of-life care for persons with advanced dementia in nursing homes compared to hospitals: a Swedish national register study. BMC palliative care. 2020;19(1):135.

12. Lundstrom S, Axelsson B, Heedman PA, Fransson G, Furst CJ. Developing a national quality register in end-of-life care: the Swedish experience. Palliat Med. 2012;26(4):313-21.

13. Svenska palliativregistret. Abbey Pain Scale - för bedömning av smärta hos personer med demenssjukdom som har svårt att beskriva sin smärta i tal.

http://media.palliativ.se/2015/08/AbbeyPalliativ2011Sve1.pdf. Accessed 8 May 2019.

14. Takai Y, Yamamoto-Mitani N, Chiba Y, Nishikawa Y, Hayashi K, Sugai Y. Abbey Pain Scale: development and validation of the Japanese version. Geriatrics \& gerontology international. 2010;10(2):145-53.

15. Gregersen M, Melin AS, Nygaard IS, Nielsen CH, Beedholm-Ebsen M. Reliability of the Danish Abbey Pain Scale in severely demented and non-communicative older patients. Int J Palliat Nurs. 2016;22(10):482-8.

16. Storti M. [The validation of a pain assessment scale for patients with cognitive impairment: the Italian version of Abbey's scale]. Recenti Prog Med. 2009;100(9):405-9.

17. Antunes B, Daveson B, Ramsenthaler C, Benalia H, Ferreira P, Bausewein C, et al. The Palliative care Outcome Scale (POS) Manual for cross-cultural adaptation and psychometric validation. London: Cicely Saunders Institute. 2012.

18. Beaton DE, Bombardier C, Guillemin F, Ferraz MB. Guidelines for the process of cross-cultural adaptation of self-report measures. Spine (Phila Pa 1976). 2000;25(24):3186-91.

19. World Health Organization. ICD-11 International Classification of Diseases 11th Revision The global standard for diagnostic health information 2019. https://icd.who.int/en. Accessed 4 March 2020. 
20. World Health Organization. ICD-11 is here! 2019. https://www.who.int/classifications/icd/en/. Accessed 4 March 2020.

21. Kallman U, Kimberly LB, Baath C. Swedish translation and validation of the international skin tear advisory panel skin tear classification system. International wound journal. 2019;16(1):13-8.

22. Socialstyrelsen. Omvårdnadslyftet Slutredovisning av regeringens kompetenssatsning 2011-2014. https://www.socialstyrelsen.se/globalassets/sharepoint-dokument/artikelkatalog/ovrigt/2015-243.pdf. Accessed 4 March 2020.

23. Socialstyrelsen. Enhetsundersökningen om äldreomsorg och kommunal hälso-och sjukvård, 2018. https://www.socialstyrelsen.se/globalassets/sharepoint-dokument/artikelkatalog/oppnajamforelser/2018-11-9-guide-for-anvandning.pdf. Accessed 4 March 2020.

24. Fry M, Chenoweth L, MacGregor C, Arendts G. Emergency nurses perceptions of the role of family/carers in caring for cognitively impaired older persons in pain: a descriptive qualitative study. Int J Nurs Stud. 2015;52(8):1323-31.

25. Fry M, Arendts G, Chenoweth L. Emergency nurses' evaluation of observational pain assessment tools for older people with cognitive impairment. J Clin Nurs. 2017;26(9-10):1281-90.

26. Sommers MS. Color awareness: A must for patient assessment 2011. https://www.americannursetoday.com/color-awareness-a-must-for-patient-assessment/. Accessed 4 March 2020.

27. Guest G, Bunce A, Johnson L. How many interviews are enough? An experiment with data saturation and variability. Field methods. 2006;18(1):59-82.

\section{Supplementary Files}

This is a list of supplementary files associated with this preprint. Click to download.

- Additionalfiles.docx 